\title{
EL CASO JORGE CASTAÑEDA GUTMAN VS. ESTADOS UNIDOS MEXICANOS ANTE LA CORTE INTERAMERICANA DE DERECHOS HUMANOS
}

\author{
Jorge Ulises CARMONA TINOCO*
}

SUMARIO: I. Introducción. II. El origen y el desarrollo jurídico del caso a nivel interno. III. La etapa internacional de tramitación del caso. IV. Comentarios conclusivos.

\section{INTRODUCCIÓN}

El 2 de septiembre de 2008, la Corte Interamericana de Derechos Humanos dio a conocer públicamente el fallo al que arribó el 6 de agosto del mismo año, sobre excepciones preliminares, fondo, reparaciones y costas en el caso Jorge Castañeda Gutman vs. Estados Unidos Mexicanos.

Con dicha sentencia la Corte da fin a un litigio iniciado el 27 de marzo de 2007, fecha en que la Comisión Interamericana planteó la demanda ante dicho tribunal. Cabe recordar que se trata del segundo caso contencioso de México ante la Corte Interamericana de Derechos Humanos, precedido por el de Alfonso Martín del Campo Dodd vs. Estados Unidos Mexicanos, que fue decidido el 3 de septiembre de 2004 a favor de las excepciones preliminares interpuestas por el Estado. ${ }^{1}$

El caso giró en torno a la violación a diversos derechos del ex canciller Jorge Castañeda Gutman, derivados de su intento por participar en las elecciones presidenciales del 2 de julio de 2006 como candidato sin

* Investigador titular en el Instituto de Investigaciones Jurídicas de la UNAM. Investigador nacional en el SNI.

1 Véase el comentario que escribe sobre este caso Campo Dodd, Alfonso Martín del, Anuario Mexicano de Derecho Internacional, México, UNAM, Instituto de Investigaciones Jurídicas, 2005, vol. V, pp. 705-723. 
apoyo de partido alguno, no obstante que a nivel federal la legislación electoral deja exclusivamente a los partidos políticos la postulación de candidatos a cargos de elección popular.

En los siguientes apartados ofreceremos un panorama del origen del asunto en el ámbito interno y de su desarrollo en el ámbito internacional hasta la sentencia de la Corte Interamericana de Derechos Humanos, con el fin de resaltar los aspectos relevantes del asunto y su impacto a nivel interno e internacional.

\section{EL ORIGEN Y EL DESARROLLO JURÍDICO DEL CASO A NIVEL INTERNO}

El 5 de marzo de 2004, Jorge Castañeda presentó un escrito ante la Dirección Ejecutiva de Prerrogativas y Partidos Políticos del Instituto Federal Electoral (IFE), en el que solicitó su registro como candidato al cargo de elección popular de presidente de los Estados Unidos Mexicanos.

Unos días después, el 12 de marzo de 2004, la mencionada oficina dio respuesta a la solicitud, en la que explicó los requisitos para proceder al registro de un ciudadano en los términos de la solicitud, básicamente que el artículo 175 del Código Federal de Instituciones y Procedimientos Electorales (Cofipe), entonces vigente, ${ }^{2}$ señalaba que correspondía a los partidos políticos la postulación de candidatos al cargo de presidente de la República, pero también añadió la autoridad electoral que existen plazos específicos que la propia ley señala para el registro de candidatos, que van del 1o. al 15 de enero de 2006.

El proceso electoral que llevó a las elecciones presidenciales de 2006 inició formalmente en octubre de $2005,{ }^{3}$ y destaca que la solicitud de Jorge Castañeda fue presentada cuando ni siquiera había iniciado el proceso electoral.

2 El 14 de enero de 2008 fue publicado un nuevo Código Federal de Instituciones y Procedimientos Electorales, derivado de la trascendente reforma constitucional del 13 de noviembre de 2007.

3 El artículo 174, párrafo 1, del Cofipe señala: "El proceso electoral ordinario se inicia en el mes de octubre del año previo al de la elección y concluye con el dictamen y declaración de validez de la elección de Presidente de los Estados Unidos Mexicanos. En todo caso, la conclusión será una vez que el Tribunal Electoral haya resuelto el último de los medios de impugnación que se hubieren interpuesto o cuando se tenga constancia de que no se presentó ninguno". 
Ante la respuesta del IFE, Castañeda interpuso un juicio de amparo el 29 de marzo de 2004 ante un juez de distrito en materia administrativa, en el que argumentaba básicamente que el artículo 175 del Cofipe era inconstitucional, por vulnerar entre otros los derechos políticos previstos en el artículo 35 constitucional. El 16 de julio de 2004 se dictó la sentencia por la cual se declaró improcedente el amparo interpuesto, con base en, entre otros, el artículo 73, fracción VII, de la Ley de Amparo, que dispone de manera expresa que este instrumento de garantía no resulta procedente contra las resoluciones de los organismos en materia electoral.

Esto llevó a Castañeda a impugnar la decisión del juez de distrito a través el recurso de revisión previsto en la Ley de Amparo. En atención al carácter de los planteamientos del peticionario, que incluía cuestiones de legalidad y de constitucionalidad, el recurso fue tramitado y decidido con relación a las primeras ante un tribunal colegiado de circuito, y a iniciativa de éste se planteó la intervención de la Suprema Corte de Justicia de la Nación (SCJN), para resolver las cuestiones de constitucionalidad.

La SCJN aceptó conocer del asunto y admitió a trámite el recurso de revisión en los temas correspondientes de constitucionalidad. El pleno de la Corte analizó el caso en sus sesiones del 8 y 16 de agosto de 2005.

En dichas sesiones, la SCJN tomó la decisión razonada de confirmar el sentido de la sentencia del juez de distrito que fue recurrida. Esto significó que el juicio de amparo fue considerado improcedente, lo que determinó su sobreseimiento definitivo. La decisión de la Suprema Corte fue tomada por Castañeda como base para considerar agotados los recursos internos y poder plantear el asunto en el ámbito internacional.

\section{LA ETAPA INTERNACIONAL DE TRAMITACIÓN DEL CASO}

\section{El procedimiento ante la Comisión Interamericana de Derechos Humanos}

El asunto de Jorge Castañeda ante los organismos del sistema interamericano inició el 17 de octubre de 2005, fecha en que la Comisión Interamericana de Derechos Humanos (CIDH) dirigió al Estado mexicano una comunicación en la que otorgaba medidas cautelares a favor de Jorge Castañeda Gutman, que consistían en ordenar a las autoridades mexica- 
nas que dicha persona fuera registrada para ser considerada candidato al cargo de presidente de los Estados Unidos Mexicanos.

En esa misma fecha, la CIDH comunicó al Estado la apertura a trámite de la petición, por supuestas violaciones a los artículos 1o., 2o., 8.1, 13, 16, 23, 24, 25, 29 y 30, todos ellos de la Convención Americana sobre Derechos Humanos, y que involucran, entre otros derechos, el acceso a la justicia, el debido proceso, la libertad de expresión, el derecho de asociación, los derechos políticos y la igualdad ante la ley.

El Estado dio respuesta a las medidas cautelares solicitadas por la Comisión, en el sentido de que no podía procederse de acuerdo con lo solicitado, esto es, inscribir sin más a Jorge Castañeda como candidato para participar en las elecciones presidenciales, en virtud de que ni siquiera la etapa de registro de candidatos estaba cercana, pues sería del 1o. al 15 de enero de 2006. En la respuesta del Estado se indicó que de presentarse a dicha etapa, su solicitud sería analizada por el Consejo General del IFE, cuyas resoluciones son impugnables ante el Tribunal Electoral del Poder Judicial de la Federación.

La Comisión Interamericana reaccionó elevando a consideración de la Corte Interamericana una solicitud de medidas provisionales, esto es, que la Comisión buscó convertir en un fallo jurisdiccional lo solicitado. No obstante lo anterior, la Corte, en su resolución del 25 de noviembre de 2005, consideró, entre otros aspectos, negar las medidas solicitadas, porque su otorgamiento habría significado "un juzgamiento anticipado por vía incidental con el consiguiente establecimiento in limine litis de los hechos y sus respectivas consecuencias objeto del debate principal".

Con la decisión de la Corte Interamericana, el proyecto de Castañeda se descarriló, pues no quedaba otra opción más que agotar el procedimiento ante la Comisión y, eventualmente, ante la Corte para determinar si sus derechos habían sido o no trasgredidos, sin que participara formalmente como candidato para presidente de la República.

El 17 de enero de 2006, el Estado presentó sus observaciones iniciales a la queja presentada por el peticionario ante la Comisión. En dicha oportunidad hizo valer, entre otras objeciones a la admisibilidad del caso, la excepción de no agotamiento de los recursos internos, y le hizo ver a la Comisión que el peticionario no se había presentado al proceso electoral en su etapa de recepción de solicitudes de registro, que culminó el 15 de enero de 2006. 
Ante esta circunstancia, la Comisión Interamericana cambió la manera en que tramita regularmente las peticiones individuales, pues se propuso que el asunto llegara a su etapa de fondo lo más pronto posible y, tal vez por esa vía, lograr que Castañeda participara en el proceso electoral, aunque éste estuviera en pleno desarrollo.

El 27 de enero de 2006 la Comisión informó que había decidido diferir el tratamiento de la admisibilidad del asunto hasta el debate y decisión sobre el fondo. A partir del 8 de mayo de 2006 la Comisión estaba en aptitud de decidir el asunto en su totalidad, pues contaba con las posiciones de las partes sobre los temas de admisibilidad y fondo.

En sus aspectos centrales, Castañeda reclamaba que el artículo 175 del Cofipe — que deja a los partidos políticos la postulación de candidatos a cargos de elección popular, entre ellos el de presidente de la República- era contrario a la Convención Americana, en especial al derecho a ser votado previsto en el artículo 23 de misma, lo que a su vez violaba la igualdad ante la ley prevista en el artículo 24, que implicaba forzarlo a unirse a un partido, lo cual era contrario a la libertad de asociación, y que se veía limitado en su libertad de expresión por tal motivo. Además, el hecho de que el amparo que interpuso haya sido improcedente significaba que no contó con acceso a la justicia, y que le fue violado en su perjuicio el debido proceso legal, ambos derechos previstos en los artículos 8o. y 25 de la Convención.

La posición del Estado era en el sentido de que el amparo es improcedente en materia electoral, y que Castañeda tenía la vía del juicio para la protección de los derechos político-electorales del ciudadano (JDC), creado en 1996, del que toca conocer y decidir al Tribunal Electoral del Poder Judicial de la Federación, para hacer sus planteamientos sobre los derechos que presuntamente le habían sido vulnerados. En cuanto al tema de fondo, el Estado sostenía que el sistema electoral, tal como estaba regulado, permite la participación política de los ciudadanos, y que el solo hecho de que sean los partidos políticos los que estén a cargo de la postulación de candidatos no es contrario a la Convención Americana, pues el sistema mexicano no exige que tales candidatos sean necesariamente miembros de los partidos que los postulan.

No obstante el tiempo record que le tomó a la Comisión instruir el expediente, la decisión del asunto le tomó cerca de seis meses, y finalmente, el 26 de octubre de 2006, emitió el Informe de fondo 113/06. 
La Comisión concluyó que el caso era admisible, y con respecto a los aspectos de fondo, determinó que el Estado mexicano no trasgredió la Convención Americana en lo que respecta a los artículos 8o., 13, 16, 23 y 24 de la Convención; esto es, no violó el debido proceso ni la libertad de expresión ni el derecho de asociación, la igualdad ante la ley, ni los derechos políticos de Jorge Castañeda, quien no había aportado elementos para acreditar que el sistema político operaba, más allá de los aspectos abstractos y normativos, en detrimento de los derechos políticos, y que el Estado había incurrido únicamente en responsabilidad internacional por la violación del derecho a la protección judicial (artículo 25), conjuntamente con las obligaciones de respeto y garantía y el deber de adoptar disposiciones de derecho interno establecidos en la Convención Americana (artículos 1(1) y 2o., respectivamente), toda vez que el amparo resultaba improcedente en materia electoral y que a través del juicio para la protección de los derechos político-electorales del ciudadano el Tribunal Electoral no podía decidir sobre los planteamientos de inconstitucionalidad de leyes electorales, debido a que tenía atribuciones acotadas por tesis de la Suprema Corte de Justicia de la Nación (tesis de jurisprudencia 25/2002 del pleno de la SCJN del 10 de junio de 2002), y la propia Ley General del Sistema de Medios de Impugnación en Materia Electoral, que en su artículo 10 señalaba como improcedentes los medios previstos en dicha ley cuando se pretenda impugnar la no conformidad a la Constitución de leyes federales o locales, lo que dejaba fuera de consideración de dicho tribunal la contrastación entre las normas electorales y la Constitución, reservado lo anterior a la propia SCJN, vía las acciones de inconstitucionalidad, previstas en el artículo 105, fracción II, de la propia Constitución mexicana.

De acuerdo con lo anterior, en dicho informe la Comisión recomendó únicamente:

1. Que el Estado adecue su ordenamiento jurídico interno de conformidad al artículos (sic) 25 de la Convención Americana, en particular las normas relevantes de la Ley de Amparo y el Cofipe, a fin de brindar un recurso sencillo y efectivo para el reclamo de la constitucionalidad de los derechos políticos.

2. Que repare adecuadamente a Jorge Castañeda Gutman por las violaciones a sus derechos humanos establecidas en el presente informe. 
El informe de fondo fue comunicado al Estado el 21 de diciembre de 2006. La Comisión concedió al Estado un plazo de dos meses para la atención de sus recomendaciones.

El 21 de febrero de 2007, el Estado fijó su postura con relación al informe de fondo 113/06, y ofreció un esquema integral para su posible atención, que consistía en la posibilidad de crear un grupo de trabajo para hacer las adecuaciones legales que había recomendado la Comisión, en el que participaría Jorge Castañeda, y además ofreció dar la debida publicidad al informe de la Comisión.

Con la decisión de la Comisión Interamericana, quedaba en claro que los planteamientos de Jorge Castañeda sobre el tema de la violación a sus derechos políticos no tenían sustento alguno, y que en todo caso el problema era el acceso a un recurso efectivo.

\section{El proceso ante la Corte Interamericana de Derechos Humanos}

La Comisión dejó de lado el ofrecimiento que hizo el Estado de poder atender sus recomendaciones y decidió demandar ante la Corte Interamericana de Derechos Humanos, únicamente por la violación que encontró al artículo 25 de la Convención Americana. El 11 de mayo de 2007 le fue notificada al Estado mexicano la demanda respecto al caso 12.535 (Jorge Castañeda Gutman), y un par de meses después el documento de los peticionarios, en los que insistían en que ahora la Corte se pronunciara sobre el resto de los derechos que habían planteado inicialmente ante la Comisión, y respecto de los cuales la misma no había encontrado violación alguna.

El Estado interpuso diversas excepciones preliminares ante la Corte, vinculadas por una parte al tema de no agotamiento de recursos internos, y por la otra, a la manera en que la Comisión Interamericana tramitó el asunto, ya que desde el punto de vista del Estado ésta no había actuado con total neutralidad.

Luego de agotada la etapa escrita del procedimiento ante la Corte, en la que las partes ofrecieron sus posiciones con relación al tema de excepciones preliminares y de fondo sobre el asunto, la Corte determinó citar a una audiencia en que se desahogarían los aspectos de excepciones y eventuales fondo y reparaciones. La audiencia fue celebrada el 8 de febrero de 2008, en la que además de ser escuchadas las partes, los jueces 
tuvieron oportunidad de hacer los planteamientos que ilustraran su criterio en el presente asunto.

En virtud de que la demanda de la Comisión sólo versaba sobre la violación al artículo 25 de la Convención, dicho órgano no podría más que circunscribirse para todos los efectos al punto de litis que planteó; en tanto, Jorge Castañeda pretendió además, demostrar la violación a sus derechos políticos y a la igualdad ante la ley. La posición del Estado fue señalar los obstáculos al ejercicio de la competencia de la Corte, y fijar su postura con relación a las pretensiones de fondo, en el sentido de que la actuación de las autoridades nacionales y el sistema electoral mexicano no trasgredían la Convención Americana.

Luego de culminada la audiencia, la Corte ofreció a las partes la oportunidad de presentar consideraciones conclusivas y sobre los aspectos que surgieron en la audiencia ante la Corte.

El proceso ante la Corte no estuvo exento de incidencias relevantes, como por ejemplo el hecho de que los peticionarios no ofrecieron en tiempo y forma las pruebas pericial y testimonial, que intentaron hacer valer en su momento, lo que llevó a la Corte a admitir sólo esta última a cargo del propio Jorge Castañeda; también es de resaltarse que la defensa de éste no aportó elementos que permitieran acreditar el daño material que alegaba había sufrido al no permitírsele participar como candidato, lo cual tendría al final un impacto negativo en las consideraciones judiciales en materia de reparación.

La sentencia fue finalmente emitida el 6 de agosto de 2008, pero no fue dada a conocer hasta el 2 de septiembre del mismo año.

\section{Aspectos relevantes del fallo de la Corte Interamericana de Derechos Humanos}

\section{A. Aspectos generales del sentido del fallo}

El fallo en principio abordó el tema de excepciones preliminares; éstas fueron una a una objeto de consideración por parte de la Corte, y al final determinó desecharlas, y por lo que respecta a la consistente en el no agotamiento de recursos internos, determinó diferir su consideración en el fondo del asunto. La decisión en materia de excepciones preliminares permitió al Tribunal entrar de manera plena al conocimiento y decisión de los aspectos de fondo. 
En el fondo, la Corte Interamericana consideró que no hubo violación a los derechos políticos ni al derecho a la igualdad ante la ley en contra de Jorge Castañeda, pero que sí fue trasgredido el artículo 25, con relación a los artículos 1o. y 2o. de la Convención. Esto es, básicamente, que el Estado, al momento de los hechos del caso, no tenía previsto en el ordenamiento interno un recurso judicial efectivo para atender los planteamientos de constitucionalidad de las leyes electorales.

Los párrafos específicos del fallo en los que se aprecian tales aspectos son los siguientes:

a) Sobre la no violación al artículo 23 de la Convención:

193. La Corte considera que el Estado ha fundamentado que el registro de candidatos exclusivamente a través de partidos políticos responde a necesidades sociales imperiosas basadas en diversas razones históricas, políticas, sociales. La necesidad de crear y fortalecer el sistema de partidos como respuesta a una realidad histórica y política; la necesidad de organizar de manera eficaz el proceso electoral en una sociedad de 75 millones de electores, en las que todos tendrían el mismo derecho a ser elegidos; la necesidad de un sistema de financiamiento predominantemente público, para asegurar el desarrollo de elecciones auténticas y libres, en igualdad de condiciones; y la necesidad de fiscalizar eficientemente los fondos utilizados en las elecciones. Todas ellas responden a un interés público imperativo. Por el contrario, los representantes no han acercado elementos suficientes que, más allá de lo manifestado en cuanto al descrédito respecto de los partidos políticos y la necesidad de las candidaturas independientes, desvirtúe los fundamentos opuestos por el Estado.

202. La Corte observa que el Estado fundamentó su afirmación de que la regulación objetada por el señor Castañeda Gutman no era desproporcionada. Por su parte, la presunta víctima no argumentó ni demostró elemento alguno que permita concluir que el requisito de ser nominado por un partido político le impuso obstáculos concretos y específicos que significaron una restricción desproporcionada, gravosa o arbitraria a su derecho a ser votado. Por el contrario, la Corte observa que el señor Castañeda Gutman incluso disponía de alternativas para ejercer su derecho a ser votado, tales como ingresar a un partido político e intentar por la vía de la democracia interna obtener la nominación y ser nominado por un partido; ser candidato externo de un partido; formar su propio partido y competir en condiciones de igualdad o, finalmente, formar una agrupación política nacional que celebre un acuerdo de participación con un partido político. 
De acuerdo a lo que consta en el expediente ante esta Corte la presunta víctima no utilizó ninguna de esas alternativas.

203. En cuanto a si la medida se ajusta al logro del objetivo legítimo perseguido, en atención a lo anteriormente mencionado, la Corte estima que en el presente caso la exclusividad de nominación por partidos políticos a cargos electivos de nivel federal es una medida idónea para producir el resultado legítimo perseguido de organizar de manera eficaz los procesos electorales con el fin de realizar elecciones periódicas, auténticas, por sufragio universal e igual, y por voto secreto que garantice la libre expresión de la voluntad de los electores de acuerdo a lo establecido por la Convención Americana.

205. Con base en los anteriores argumentos, la Corte no considera probado en el presente caso que el sistema de registro de candidaturas a cargo de partidos políticos constituya una restricción ilegítima para regular el derecho a ser elegido previsto en el artículo 23.1.b de la Convención Americana y, por lo tanto, no ha constatado una violación al artículo 23 de dicho tratado.

b) Sobre la no violación al artículo 24 de la Convención:

207. Los representantes, entre otros argumentos, señalaron que el artículo 175 del Cofipe "contiene restricciones, no solamente excesivas, sino innecesarias en una sociedad como la mexicana, que pretende ser democrática" e indicaron que "los Estados de Sonora y Yucatán cuentan con legislaciones electorales que permiten las candidaturas independientes, y que la Suprema Corte de Justicia de la Nación, [las] ha considerado como permisibles en el régimen constitucional mexicano.

212. La Corte estima que las elecciones locales y las federales no son comparables, de modo que no es posible concluir que las diferencias de organización entre unas y otras, sean discriminatorias y violen el derecho a la igualdad ante la ley establecido en el artículo 24 de la Convención Americana.

Por otro lado, la decisión de la Corte Interamericana reconoció que en México el amparo es improcedente en materia electoral y, por lo tanto, no era la vía adecuada a la que debía acudir el peticionario a reclamar su derecho, como se aprecia en el siguiente párrafo del fallo: "91. La Corte considera, al igual que la Comisión y el Estado, que el recurso de amparo interpuesto por la presunta víctima no era la vía adecuada en ese caso, dada su improcedencia en materia electoral". 
Por lo que respecta al juicio para la protección de los derechos político-electorales del ciudadano (JDC), la Corte señaló que si bien el Tribunal Electoral del Poder Judicial de la Federación (TEPJF), al interpretar el Cofipe entonces vigente, en sus artículos 79 y 80, estableció que cualquier persona está legitimada para acudir al JDC, en la práctica se traduce en que sólo quienes previamente hayan sido postulados por un partido político pueden acudir a dicho juicio; por lo tanto, dicho juicio, en opinión de la Corte, no le fue accesible al peticionario.

Por otra parte, la Corte también se ocupó de si el JDC era o no un recurso efectivo en términos del artículo 25 de la Convención Americana. Sobre el particular, decidió que el TEPJF no tenía al momento de los hechos, reconocida competencia para analizar la compatibilidad de normas electorales frente a la Constitución (derivada básicamente de tesis de la SCJN de 2002, que habían sido duramente criticadas por la doctrina), por lo que en opinión de la Corte, acudir al TEPJF no representaba entonces un recurso efectivo en el caso concreto. Los párrafos 130 y 131 ilustran este punto:

130. Para ser capaz de restituir a la presunta víctima en el goce de sus derechos en ese caso, el juicio para la protección de los derechos político-electorales del ciudadano debía posibilitar a la autoridad competente evaluar si la regulación legal establecida en el Código Federal en materia electoral, y que alegadamente restringía de forma no razonable los derechos políticos de la presunta víctima, era compatible o no con el derecho político establecido en la Constitución, lo que en otras palabras significaba revisar la constitucionalidad del artículo 175 del Cofipe. Ello no era posible, según se señaló anteriormente, por lo que el Tribunal Electoral, conforme a la Constitución y los criterios obligatorios de la Suprema Corte de Justicia, no tenía competencia para analizar la compatibilidad de disposiciones legales en materia electoral con la Constitución.

131. Dado que el recurso de amparo no resulta procedente en materia electoral, la naturaleza extraordinaria de la acción de inconstitucionalidad y la inaccesibilidad e inefectividad del juicio de protección para impugnar la falta de conformidad de una ley con la Constitución, en la época de los hechos del presente caso no había en México recurso efectivo alguno que posibilitara a las personas cuestionar la regulación legal del derecho político a ser elegido previsto en la Constitución Política y en la Convención Americana. En razón de ello, la Corte concluye que el Estado no ofreció a la presunta víctima un recurso idóneo para reclamar la alegada violación de su derecho político a ser elegido, y por lo tanto violó el artículo 25 de 
la Convención Americana, en relación con el artículo 1.1 del mismo instrumento, en perjuicio del señor Castañeda Gutman.

Lo anterior, además, significó, en opinión de la Corte, que el Estado incumplió su deber genérico de contar con disposiciones de derecho interno para hacer efectivo el artículo 25 de la Convención, por lo que la violación a este precepto se vincula con lo dispuesto por el artículo 10. de la Convención.

\section{B. Autoridades, en el ámbito interno, cuyos actos u omisiones} habrían originado la violación al artículo 25 de la Convención, declarada por la Corte Interamericana a la Convención Americana

En primer lugar, habría que mencionar a la Suprema Corte de Justicia de la Nación, en virtud de las tesis de 2002, que limitaron la posibilidad de que el TEPJF pudiera ejercer un control incluso difuso de la constitucionalidad de las leyes electorales, no obstante que dicho tribunal ya había llevado a cabo dicha labor antes de la emisión de las tesis mencionadas (párrafos 124 y 125 de la sentencia).

En segundo lugar, el asunto atañe al Congreso de la Unión, al implicar en el artículo 80 de la Ley General del Sistema de Medios de Impugnación en Materia Electoral, que sólo quienes hayan sido postulados previamente por un partido político podían acudir al JDC para reclamar su derecho a ser votado, no obstante que el TEPJF intentó allanar dicha cuestión al interpretar dicho precepto de manera armónica con el artículo 79 de dicho ordenamiento (párrafo 114).

En tercer lugar, el Tribunal Electoral, al decidir en 2006 el JDC $67 / 2006$ en el caso del señor Héctor Montoya, en virtud de que se abstuvo de conocer el fondo del asunto con base en las tesis de la SCJN, y confirmó que no estaba facultado para desaplicar disposiciones electorales que considerara inconstitucionales. De haber entrado al fondo en dicho asunto, así no se le hubiera dado al final la razón al solicitante del JDC, se tendría una prueba fehaciente de la accesibilidad y eficacia de dicho juicio en casos similares (párrafo 126). 


\section{Efectos o consecuencias del fallo}

Las sentencias de la Corte Interamericana son de cumplimiento obligatorio, definitivas e inatacables. En los casos en que declaran alguna violación a la Convención, surge el tema de la reparación.

En el presente caso, la Corte no otorgó reparación alguna por daño material o inmaterial a favor de Jorge Castañeda (párrafos 221 y 225), en especial porque sus abogados sólo probaron supuestos daños en torno a la violación al artículo 23, y no al 25 de la Convención. No obstante, como medidas de satisfacción, la Corte tomó nota de la reforma constitucional del 13 de noviembre de 2007 (párrafo 230), por virtud de la cual se dio a la Sala Superior y a las salas regionales del Tribunal la posibilidad de desaplicar normas que consideraran contrarias a la Constitución (artículo 99 constitucional), de manera que únicamente solicitó al Estado que éstas se vean reflejadas en la legislación secundaria, que sería en especial en la Ley General del Sistema de Medios en Materia Electoral, a efecto de que vía el JDC los ciudadanos puedan en forma efectiva plantear cuestionamientos de inconstitucionalidad del Cofipe frente al derecho a ser elegidos (párrafo 231).

La Corte tampoco ordenó al Estado, como lo solicitó la Comisión, un reconocimiento público de responsabilidad a manera de disculpa, pero sí decretó la publicación de partes de la sentencia, por una sola vez, en específico los párrafos 77 a 133, en el Diario Oficial de la Federación y en un periódico de circulación nacional.

Por último, la Corte consideró el tema de gastos y costas, y en virtud de que el peticionario sólo acreditó gastos con motivo de la audiencia de febrero de 2008 en San José, Costa Rica, determinó que procedía cubrirle el equivalente a "US $\$ 7000$ (siete mil), dólares americanos" (párrafo 244), con relación al traslado, hospedaje y estancia de quienes integraron la delegación que acreditó ante la Corte.

\section{Plazo concedido al Estado para acatar el fallo y seguimiento de la Corte}

La Corte determinó que las adecuaciones normativas ordenadas se lleven a cabo en un "plazo razonable" (párrafo 231); la publicación de la sentencia en un plazo de seis meses (párrafo 235); para el pago de la cantidad por concepto de gastos y costas, se otorgó un plazo de seis meses (párrafo 245). 
La Corte Interamericana solicitó al Estado, que en el plazo de un año presentara un informe sobre cómo ha cumplido con el fallo (párrafo 250), a lo cual el propio tribunal daría seguimiento.

\section{COMENTARIOS CONCLUSIVOS}

Si bien el caso de Jorge Castañeda generó mucha expectativa en diversos círculos y en los medios de comunicación, en especial sobre el posible impacto de sus planteamientos en el tema de las candidaturas sin postulación de partidos o "candidaturas independientes", a final de cuentas la Corte Interamericana únicamente confirmó, aunque con base en un análisis diferente, la conclusión a la que había llegado la Comisión Interamericana, que únicamente podía identificarse como violación a la Convención Americana el hecho de que en México los ciudadanos no tenían acceso a un recurso efectivo para poder plantear la constitucionalidad de las normas electorales.

Cabe destacar que la decisión de la Corte Interamericana fue adoptada por unanimidad, mientras que la de la Comisión Interamericana fue una decisión dividida, y que para algunos comisionados sí existía, además de la violación al artículo 25 de la Convención, trasgresión al derecho de participación política previsto en el artículo 23 de la Convención.

Uno de los planteamientos del Estado para sostener la existencia de un recurso accesible y efectivo en el caso concreto fue que el Tribunal Electoral, si bien tenía acotadas atribuciones en materia de un tipo específico de control constitucional de leyes, podía sin embargo llevar a cabo un control de convencionalidad del Cofipe; esto es, que estaba facultado para conocer y decidir en el ámbito interno si este último ordenamiento era o no contrario a la Convención Americana y, en caso de ser incompatible, aplicar directamente esta última al caso concreto.

El párrafo 129 de la sentencia es ilustrativo a este respecto:

129. Por último cabe señalar que si bien el Estado alegó que "acceder al Trife habría significado... una forma interna de control convencional de las leyes", lo cual "deja fuera de toda duda la existencia de un recurso judicial adecuado y eficaz de protección de derechos humanos de índole política", esta Corte observa que, a diferencia de los casos mencionados por el Estado como los de los señores Hank Rhon, Manuel Guillén Monzón, María Mercedes Maciel y Eligio Valencia Roque, en el caso del señor 
Castañeda Gutman no está probado en el expediente ante esta Corte que el Trife hubiera podido realizar tal "control convencional" respecto de una ley federal electoral.

Así, la Corte Interamericana consideró que en el expediente del caso en cuestión no existían elementos para determinar que el TEPJF podía llevar a cabo tal ejercicio frente a un ordenamiento federal, lo cual en nuestro concepto no es exacto, toda vez que el caso Castañeda habría sido el primero en que se planteara una cuestión de tal naturaleza, como se indicó en su momento a la Corte Interamericana, que conocía la actuación del Tribunal Electoral en otros casos que involucraban disposiciones de índole constitucional local frente a la Constitución federal y la Convención Americana. De hecho, el control de convencionalidad de las leyes en el ámbito interno es una de las vías que deben ser fortalecidas a efecto de lograr una aplicación efectiva de los estándares internacionales de derechos humanos por las autoridades nacionales y, por supuesto, sujeto a revisión ulterior en los casos que lleguen a conocimiento de la Corte Interamericana.

En lo que concierne al cumplimiento de la decisión de la Corte, cabe hacer notar que las adecuaciones a la legislación secundaria con relación a las reformas constitucionales de noviembre de 2007 ya habían sido llevadas a la Ley General del Sistema de Medios de Impugnación en Materia Electoral y publicadas en el Diario Oficial de la Federación del 10. de julio de 2007, con respecto a las atribuciones de la Sala Superior y las salas regionales en materia de desaplicación de normas contrarias a la Constitución.

Por último, con relación al pago de los gastos y costas incluidos en el apartado de reparaciones de la sentencia, cabe hacer notar que se cuenta con un procedimiento para tal efecto, derivado de la reforma al artículo 113 constitucional publicada el 14 de junio de 2002 (en vigor a partir del 1o. de enero de 2005), y la posterior ley reglamentaria de dicho precepto publicada el 31 de diciembre de 2004, que reguló dicho aspecto. ${ }^{4}$

4 Véase Carmona Tinoco, Jorge Ulises, "El marco jurídico e institucional mexicano para atender las recomendaciones de la Comisión Interamericana de Derechos Humanos y cumplir con las sentencias de la Corte Interamericana de Derechos Humanos", en Méndez Silva, Ricardo (coord.), Derecho Internacional de los Derechos Humanos. Culturas y Sistemas Jurídicos Comparados, México, UNAM, 2008, t. I, pp. 335-396. 
El artículo 113 constitucional señala en su párrafo segundo: "La responsabilidad del Estado por los daños que, con motivo de su actividad administrativa irregular, cause en los bienes o derechos de los particulares, será objetiva y directa. Los particulares tendrán derecho a una indemnización conforme a las bases, límites y procedimientos que establezcan las leyes".

Confirma lo anterior el contenido del artículo 2o. de la Ley, que ordena que ésta será aplicable "para cumplimentar los fallos de la Corte Interamericana de Derechos Humanos, así como las recomendaciones de la Comisión Interamericana de Derechos Humanos, aceptadas estas últimas por el Estado Mexicano, en cuanto se refieran a pago de indemnizaciones".

La decisión de la Corte Interamericana en el caso Castañeda seguramente será objeto de análisis minuciosos, los que darán cuenta de los diversos precedentes que el caso genere en aspectos de procedimiento y de fondo, y si bien no puede descartarse que se trata de un asunto relevante, hay que recordar que también se encuentran ante la Corte otros casos de mayor entidad respecto de México, como son el de las muertes de mujeres en Ciudad Juárez, Chihuahua, y el de la desaparición forzada de Rosendo Radilla, ocurrida en la década de los setenta, cuyos desenlaces posiblemente ocurran en 2009. 